\title{
Environmental conditions of Jiaozhou Bay, 1981
}

\author{
Dongfang Yang ${ }^{1,2,3, ~ a ~, ~ S i x i ~ Z h u ~}{ }^{1,2}$, \\ Xiaoli Zhao ${ }^{1,2}$, Yunjie $\mathrm{Wu}^{1,2}$ and Fengyou Wang ${ }^{1,2, b}$ \\ ${ }^{1}$ Research Center for Karst Wetland Ecology, Guizhou Minzu University, Guiyang 550025, China; \\ ${ }^{2}$ College of Chemistry and Environmental Science, Guizhou Minzu University, Guiyang 550025, \\ China; \\ ${ }^{3}$ North China Sea Environmental Monitoring Center, SOA, Qingdao 266033, China. \\ adfyang_dfyang@126.com, ${ }^{b}$ corresponding authorfywang@yahoo.com.cn
}

\begin{abstract}
Keywords: Environment condition; Pollution source; Transfer process; Distribution; Jiaozhou Bay Abstract. This paper analyzed the distributions and transfer processes of $\mathrm{Cd}, \mathrm{As}, \mathrm{Cr}, \mathrm{Pb}, \mathrm{HCH}, \mathrm{Hg}$ and PHC in Jiaozhou Bay 1981. In according to the contents, horizontal and vertical distributions, and seasonal distributions of these pollutants, their water quality conditions, pollution sources, as well as the transfer processes were revealed. Furthermore, the atmosphere transfer process, land transfer process and waters transfer process of these pollutants were proposed and applied in the understanding of their transferring in waters. The aim of this paper was to provide all-dimensional, multi-angle, and comprehensive enlightenment to the environmental research in Jiaozhou Bay.
\end{abstract}

\section{Introduction}

With the rapid development of economic, both industry and agriculture are also increasing rapidly, so as their production and consumption. Hence, the environments of land, atmosphere and waters have long been suffering from various pollutants. $\mathrm{Cd}, \mathrm{As}, \mathrm{Pb}, \mathrm{HCH}, \mathrm{Hg}$ and $\mathrm{PHC}$ are among the critical environmental pollutants due to the features of degradation-resistant, persistent in the environment, and toxic to human and ecosystem, etc. Hence, understanding the existence situation and transfer law of these pollutants is essential to the research on their transfer process in waters [1-23].

Jiaozhou Bay $\left(35^{\circ} 55^{\prime}-36^{\circ} 18^{\prime} \mathrm{N}, 120^{\circ} 04^{\prime}-120^{\circ} 23^{\prime} \mathrm{E}\right)$ is located in the south of Shandong Peninsula, eastern China. It is a semi-closed natural bay, whose area, bay mouth width average water depth and maximum water depth are $390 \mathrm{~km}^{2}, 2.5 \mathrm{~km}, 7 \mathrm{~m}$ and $50 \mathrm{~m}$, respectively. This bay is surrounding by cities of Qingdao, Jiaozhou and Jiaonan in the east, north and south, respectively (Fig. 1). There are more than ten inflow rivers, including Dagu River, Haibo River, Licun River, Loushan River, etc., all of then are seasonal rivers. The water quality condition of this bay has been degrading due to the lag of environmental protection to the economic growth.

The investigation on $\mathrm{Cd}, \mathrm{As}, \mathrm{Cr}, \mathrm{Pb}, \mathrm{HCH}, \mathrm{Hg}$ and $\mathrm{PHC}$ in Jiaozhou Bay waters was conducted by North China Sea Environmental Monitoring Center in April, August and November 1981 [11-23], representing spring, summer, and winter, respectively. The measurement of these pollutants was follow by National Specification for Marine Monitoring [24]. This paper analyzed the water quality conditions, pollution sources, as well as the transfer processes of $\mathrm{Cd}, \mathrm{As}, \mathrm{Cr}, \mathrm{Pb}, \mathrm{HCH}, \mathrm{Hg}$ and $\mathrm{PHC}$ 
from the aspects of contents, horizontal and vertical distributions, and seasonal distributions [11-23]. In addition to reveal the environmental conditions of Jiaozhou Bay 1981, the objects of this paper was to provide theoretical basis for pollution prevention and control.

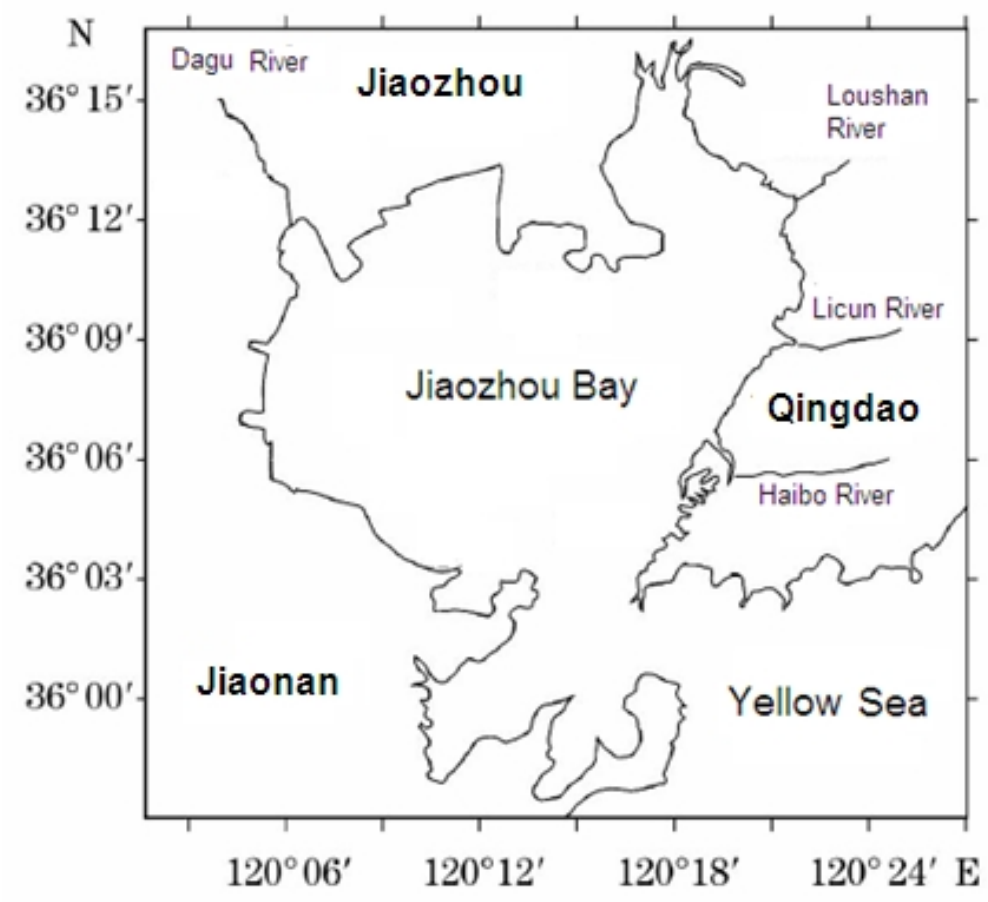

Fig.1 Geography location of Jiaozhou Bay

\section{Results}

Cd contents in Jiaozhou Bay waters in 1981 were lower than the guide line of Category I for Cd $\left(1.0 \mu \mathrm{g} \mathrm{L}^{-1}\right)$ in National Standard of China for Seawater Quality (GB3097-1997), indicated that this bay Jiaozhou Bay had not been contaminated by Cd in 1981. There were two major source of Cd in Jiaozhou Bay, one was atmosphere deposition, whose source strength was $0.00-0.55 \mu \mathrm{g} \mathrm{L}^{-1}$, another was runoff, whose source strength was $0.00-0.40 \mu \mathrm{g} \mathrm{L}^{-1}$. However, the source strengths of these two sources were very low in autumn.

As contents in Jiaozhou Bay surface waters and bottom waters in 1981 were $1.00-2.70 \mu \mathrm{g} \mathrm{L}^{-1}$ and 1.00-2.40 $\mu \mathrm{g} \mathrm{L}^{-1}$, respectively, both of which were more lower than Category I for As $\left(20.0 \mu \mathrm{g} \mathrm{L}^{-1}\right)$ in National Standard of China for Seawater Quality (GB3097-1997), indicated that this bay Jiaozhou Bay had not been contaminated by As in 1981. As in this bay was mainly sourced from runoff, whose source strength was lower than $2.70 \mu \mathrm{g} \mathrm{L}^{-1}$, the reason was that the soil, air and waters in Jiaozhou Bay Region had not been polluted by As in study year. As contents in surface and bottom waters were closed in the aquatic transfer process. As contents in surface waters were higher in summer than in spring, while for bottom waters were closed.

Cr contents ranged from $0.48-32.32 \mu \mathrm{g} \mathrm{L}^{-1}$, and were lower than Category I for $\mathrm{Cr}\left(50.0 \mu \mathrm{g} \mathrm{L}^{-1}\right)$ in National Standard of China for Seawater Quality (GB3097-1997), indicated that this bay Jiaozhou Bay had not been contaminated by $\mathrm{Cr}$ in 1981. River runoff was the major source of $\mathrm{Cr}$, whose 
source strengths in the estuaries and coastal waters were $0.48-32.32 \mu \mathrm{g} \mathrm{L}^{-1}$ and $0.18-1.85 \mu \mathrm{g} \mathrm{L}^{-1}$, respectively.

$\mathrm{Pb}$ contents ranged from $0.00-3.40 \mu \mathrm{g} \mathrm{L}^{-1}$, and were lower than Category II for $\mathrm{Pb}\left(5.0 \mu \mathrm{g} \mathrm{L}^{-1}\right)$ in National Standard of China for Seawater Quality (GB3097-1997), indicated that this bay Jiaozhou Bay had not slightly contaminated by $\mathrm{Pb}$ in 1981. There were some high value regions for $\mathrm{Pb}$ contents, such as coastal areas in the southwest, center waters in the northeast, coastal areas of the top of the islands, and the river mouth of Haibo River. It could be found that stream flow, overland runoff and atmosphere deposition were the major sources of $\mathrm{Pb}$ in Jiaozhou Bay. In according to the horizontal, vertical and seasonal distributions, we found that the sink of $\mathrm{Pb}$ in Jiaozhou Bay was the bottom waters in the bay mouth, in where $\mathrm{Pb}$ contents were increasing. The transfer process of $\mathrm{Pb}$ was that, $\mathrm{Pb}$ contents was continuously decreasing with time, as $\mathrm{Pb}$ was discharged into surface, and then to water body, and finally to the bottom.

For temporal scale, $\mathrm{HCH}$ contents in both surface waters and bottom waters were higher in summer than in spring. The seasonal distribution of $\mathrm{HCH}$ showed that $\mathrm{HCH}$ contents were relative high in summer yet were relative low in spring. For spatial scale, $\mathrm{HCH}$ contents were relative high in river mouths of Haibo River, Licun River and Loushan River, indicated that $\mathrm{HCH}$ were mainly from non-point source. For vertical distributions, it was found that the higher $\mathrm{HCH}$ contents in surface water the higher $\mathrm{HCH}$ contents in bottom waters. The reason was the sedimentation of $\mathrm{HCH}$.

$\mathrm{Hg}$ contents in in spring, summer, and autumn ranged from $0.028-2.086 \mu \mathrm{g} \mathrm{L}^{-1}, 0.001-0.040 \mu \mathrm{g} \mathrm{L}^{-1}$, and 0.002-0.017 $\mu \mathrm{g} \mathrm{L}^{-1}$, respectively. In spring, $\mathrm{Hg}$ in Jiaozhou Bay was mainly sourced from the overland runoff coast in the east, yet the sources of $\mathrm{Hg}$ in summer and autumn were neglect-able. For seasonal distributions, $\mathrm{Hg}$ contents were in order of spring > summer $>$ autumn. From the point of view of pollution control, it was necessary to control the emission of $\mathrm{Hg}$ in spring.

In comparison with the other pollutants, PHC contents were showing significant seasonal and spatial variations in 1981. In according to National Standard of China for Seawater Quality (GB3097-1997), PHC contents in Jiaozhou Bay were confirmed to Grade II, III, IV and worse than IV. The horizontal distribution of PHC showed that PHC contents were relative high in estuaries of the major inflow rivers such as Haibo River, Licun River, Loushan River, as well as Dagu River, indicated river flows were major input channels of PHC. Meanwhile, PHC contents were decreasing from the estuaries along with the flow direction. For seasonal distribution, PHC contents were relatively high in spring and summer, yet were relative low in autumn. In case of high PHC contents in waters, the distributions of PHC in surface and bottom waters were consistent, due to the sedimentation of PHC. While for low PHC contents in waters, the distributions of PHC in surface and bottom waters were inverse, because PHC was settling and accumulating in bottom waters with time and increasing in autumn, yet PHC content in surface waters in autumn was little and decreasing.

\section{Discussion}

The contents the study pollutants were showing their pollution levels in 1981. For Cd, As and Cr, their contents in the whole year were all confirmed to the guide line of Grade I in National Standard 
of China for Seawater Quality (GB3097-1997). The pollution level of Pb was confirmed to Grade II. $\mathrm{Hg}$ contents in spring were belong to Grade III, for summer and autumn were Grade I. HCH contents in most areas were confirmed to Grade I, yet in the estuaries were ranged from Grade II to III. PHC contents were confirmed to Grade II, III, IV and worse than IV. In general, the pollution level of the pollutants could be sorted as $\mathrm{Cd}<\mathrm{As}<\mathrm{Cr}<\mathrm{Pb}<\mathrm{Hg}<\mathrm{HCH}<\mathrm{Hg}<\mathrm{PHC}$.

The sources of different pollutants were also different. There were two major source of $\mathrm{Cd}$ in Jiaozhou Bay, one was atmosphere deposition, another one was runoff. However, the source strengths of these two sources were very low in autumn. As and $\mathrm{Cr}$ were both mainly sourced from runoff, whose source strength was very weak. $\mathrm{HCH}$ contents were relative high in river mouths of Haibo River, Licun River and Loushan River, indicated that $\mathrm{HCH}$ were mainly from non-point source. Stream flow, overland runoff and atmosphere deposition were the major sources of $\mathrm{Pb}$, and the source strength of atmosphere deposition was relative strong. $\mathrm{Hg}$ was mainly sourced from the overland runoff coast in the east, yet the sources of $\mathrm{Hg}$ in summer and autumn were neglect-able. PHC contents were relative high in estuaries of the major inflow rivers such as Haibo River, Licun River, Loushan River, as well as Dagu River, indicated river flows were major input channels of PHC.

In according to the contents and the major pollution sources of $\mathrm{Cd}, \mathrm{As}, \mathrm{Cr}, \mathrm{Pb}, \mathrm{HCH}, \mathrm{Hg}$, and $\mathrm{PHC}$, it could be found that the influences of human activities on the environmental condition of Jiaozhou Bay were showing seasonal variations.

Table 1 Seasonal changes of water environmental quality in Jiaozhou Bay

\begin{tabular}{llll}
\hline Pollutant & spring & summer & sutumn \\
\hline $\mathrm{Cd}$ & Non-pollution & Non-pollution & Non-pollution \\
$\mathrm{As}$ & Non-pollution & Non-pollution & \\
$\mathrm{Cr}$ & Mild-pollution & Non-pollution & Non-pollution \\
$\mathrm{Pb}$ & Mild-pollution & Mild-pollution & Mild-pollution \\
$\mathrm{HCH}$ & Mild-pollution & Moderate-pollution & \\
$\mathrm{Hg}$ & Heavy-pollution & Non-pollution & Non-pollution \\
$\mathrm{PHC}$ & Heavy-pollution & Heavy-pollution & Moderate-pollutio \\
& & & $\mathrm{n}$ \\
\hline
\end{tabular}

Taking $\mathrm{Cd}, \mathrm{As}, \mathrm{Cr}, \mathrm{Pb}, \mathrm{HCH}, \mathrm{Hg}$, and $\mathrm{PHC}$ as substances. Based on their temporal, horizontal and vertical distributions, their transfer processes could be further defined as atmosphere transfer process, land transfer process and aquatic transfer process. The atmosphere transfer could be divided in three stages as 1) the substances were discharged to the air, 2) the substances were delivered over the sea waters, and 3) the substances were depositing to sea waters. For instance, atmosphere deposition was the major source of $\mathrm{Cd}$ and $\mathrm{Pb}$ in study area. The land transfer could also be divided in three stages as 1) the substances were discharged to the land and land waters, 2) the substances were delivered to the major streams, and 3) the substances were delivered to the sea waters by the major streams. For instance, the major inflow rivers such as Haibo River, Licum River and Loushan River were the major input channels of the pollutants to the bay. The aquatic 
transfer could also be divided in three stages as 1) the substances were delivered to the sea waters by various pollution sources, 2) the substances were delivered to the surface waters in the bay, and 3) the substances were transferring to the sea bottom by sedimentation. For instance, the major inflow rivers such as Haibo River, Licum River and Loushan River were the major input channels of the pollutants to the bay.

Along with the increasing of the reproduction of marine organism in spring, the biomass is also increasing rapidly, both the reproduction and biomass are reaching the climax in summer [25], and a large amount of colloid are generating. Hence, the adsorption capacity of the suspended particulate matter is enhancing, and the sedimentation of the substances is also enhancing. However, the sedimentation of the substances is decreasing in autumn due to the decreasing of temperature. In generally, the spatial-temporal distributions of the substances were determined by pollution sources, water exchange and sedimentation.

\section{Conclusions}

In according to the contents, horizontal and vertical distributions, and seasonal distributions of $\mathrm{Cd}$, As, $\mathrm{Cr}, \mathrm{Pb}, \mathrm{HCH}, \mathrm{Hg}$ and PHC in Jiaozhou Bay 1981, we found that $\mathrm{Cd}$, As and $\mathrm{Cr}$, were confirmed to Grade I in National Standard of China for Seawater Quality (GB3097-1997), Pb was confirmed to Grade II, Hg was belong to Grade I to III, HCH in most areas confirmed to Grade I, yet in the estuaries were ranged from Grade II to III. PHC contents were confirmed to Grade II, III, IV and worse than IV. In general, the pollution level of the pollutants could be sorted as $\mathrm{Cd}<\mathrm{As}<\mathrm{Cr}<\mathrm{Pb}$ $<\mathrm{Hg}<\mathrm{HCH}<\mathrm{Hg}<\mathrm{PHC}$.

The sources of different pollutants were also different. Atmosphere deposition and runoff were two major source of $\mathrm{Cd}$. As and $\mathrm{Cr}$ were both mainly sourced from runoff. $\mathrm{HCH}$ and $\mathrm{PHC}$ were mainly from non-point source by stream flow. Stream flow, overland runoff and atmosphere deposition were major sources of $\mathrm{Pb}$. $\mathrm{Hg}$ was mainly sourced from the overland runoff coast in the east. In according to the contents and the major pollution sources of these pollutants, it could be found that the influences of human activities on the environmental condition were showing seasonal variations.

Based on the temporal, horizonal and vertical distributions of the substances, and transfer processes could be further defined as atmosphere transfer process, land transfer process and aquatic transfer process. In according to these transfer processes, we could provide all-dimensional, multi-angle, and comprehensive enlightenment to the environmental research in Jiaozhou Bay.

\section{Acknowledgement}

This research was sponsored by Doctoral Degree Construction Library of Guizhou This research was sponsored by Doctoral Degree Construction Library of Guizhou Nationalities University, Education Ministry's New Century Excellent Talents Supporting Plan (NCET-12-0659), Project of Outstanding Technological Educators of Governor of Guizhou ([2012]71), Project of Low Carbon Technology Plan of Guiyang (2012205]), Project of Science and Technology Foundation of 
Guiyang (LKM[2012]05), Special Research Projects of High Level Talents of Guizhou Province (TZJF-2011- 44), and Research Projects of Guizhou Nationalities University ([2014]02).

\section{Reference}

[1] Yang DF, Cao HR, Gao ZH, et al.: Marine Science, Vol. 27 (2008), p. 37-39. (in Chinese)

[2] Yang DF, Gao ZH, Sun JY, et al.: Coastal Engineering, Vol. 27(2008), p. 48-53. (in Chinese)

[3] Yang DF, Su C, Gao ZH, et al.: Chinese Journal of Oceanology and Limnology, Vol. 26 (2008), p: 296-299.

[4] Yang DF, Chen Y, Wang H, et al.: Coastal Engineering, Vol. 29 (2010), p. 73-82. (in Chinese)

[5] Yang DF, Gao ZH, Cao HR, et al.: Coastal Engineering, Vol. 27 (2008), p. 65-71. (in Chinese)

[6] Yang DF, Zhang YC, Zou J, et al.: Open Journal of Marine Science, Vol. 2 (2011), p. 108-112

[7] Yang DF, Chen Y, Chang YX, et al.: Coastal Engineering, Vol. 32 (2013), p. 68-78. (in Chinese)

[8] Yang DF, Guo JH, Zhang YJ, et al.: Journal of Water Resource and Protection, Vol. 3(2011), p. 41-49.

[9] Yang DF, Wang LL, Gao ZH, et al.: Marine Science, Vol. 28 (2009), p. 501-505. (in Chinese)

[10] Yang DF, Sun PY, Chen C, et al.: Coastal Engineering, Vol. 32 (2013), p. 60-72. (in Chinese)

[11] Chen Y, Zhang JY, Guo JH, et al.: Ocean Development and Management, Vol. 30 (2013), p. 81-83. (in Chinese)

[12] Yang DF, Gao ZH, Sun PY, et al.: Coastal Engineering, Vol. 28 (2009), p. 69-77. (in Chinese)

[13] Yang DF, Song WP, Chen ST, et al.: Coastal Engineering, Vol. 31(2012): p. 47- 55. (in Chinese)

[14] Yang DF, Gao ZH, Cao HR, et al.: Coastal Enginering, Vol. 27(2008): 65-71. (in Chinese)

[15] Yang DF, Gao ZH, Sun PY, et al.: Coastal Enginering, Vol. 28(2009): 69-77. (in Chinese)

[16] Yang DF, Zhu SX, Wu YF, et al.: Applied Mechanics and Materials, Vols.644-650 (2014), p. 5325-5328.

[17] Yang DF, Wang FY, Wu YF, et al.: Applied Mechanics and Materials, Vol.644-650 (2014), p. 5329-5312.

[18]Chen Y, Yu QG, Li TJ, et al.: Applied Mechanics and Materials, Vol.644-650 (2014), p. 5329-5332.

[19] Yang DF, Zhu SX, Wang FY, et al.: Applied Mechanics and Materials, Vol.651-653 (2014), p. 1419-1422.

[20] Yang DF, Geng X, Chen ST, et al.: Applied Mechanics and Materials, Vol.651-653( 2014), p.1216-1219.

[21] Yang DF, Sun PY, Ju L, et al.: Applied Mechanics and Materials, Vol.644-650 (2014), p. 5312-5315.

[22] Yang DF, Wu YF, He HZ, et al.: Proceedings of the 2015 international symposium on computers and informatics (2015), p. 2647-2654.

[23] Yang DF, Sun PY, Ju L, et al.: Proceedings of the 2015 international symposium on computers and informatics (2015), p. 2647-2654.

[24] State Ocean Administration. The specification for marine monitoring: Beijing, Ocean Precess, (1991).

[25] Yang DF, Wang F, Gao ZH, et al.: Marine Science, Vol. 28(2004):71-74. 